\title{
The End of Population Growth in Asia
}

Wolfgang Lutz (lutz@iiasa.ac.at)

Sergei Scherbov (scherbov@iiasa.ac.at)

\section{Approved by}

Leen Hordijk (hordjik@iiasa.ac.at)

Director

August 29, 2002

Interim Reports on work of the International Institute for Applied Systems Analysis receive only limited review. Views or opinions expressed herein do not necessarily represent those of the Institute, its National Member Organizations, or other organizations supporting the work. 


\section{Contents}

Different Approaches to Probabilistic Population Projections ......................................... 2

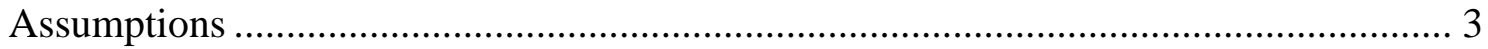

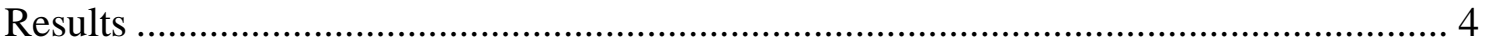

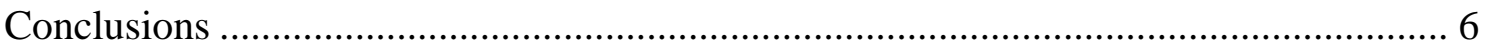

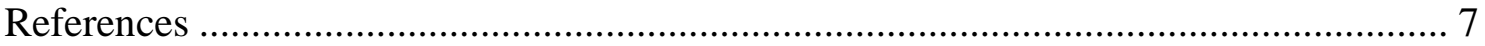




\section{Abstract}

This paper presents probabilistic population projections for five regions of Asia (South Asia, Central Asia, China region, Pacific OECD and Pacific Asia) and Asia as a whole. Over this century, Asia will experience a very heterogeneous demographic development: Central Asia is still expected to almost double its population and South Asia will become by far the world's most populous region, rapidly surpassing the China region. Simultaneously, today's Pacific OECD countries are likely to shrink in size and experience extreme population aging. The proportion of the population above age 60 in these countries (with Japan having the greatest weight) is expected to reach an incredible 50 percent of the total population (with the 95 percent uncertainty interval ranging from 35 to 61 percent). The China region will experience a more rapid speed of aging with the proportion above age 60 expected to increase by a factor of four from 10 percent in 2000 to 39 percent in 2100 . 


\section{Acknowledgments}

This paper was presented at the international workshop on "Fertility Decline, Below Replacement Fertility and the Family in Asia: Prospects, Consequences and Policies," organized by the Asian MetaCentre for Population and Sustainable Development Analysis, and the Family Studies Research Programme, National University of Singapore, and held in Singapore from 10-12 April, 2002. 


\title{
The End of Population Growth in Asia
}

\author{
Wolfgang Lutz and Sergei Scherbov
}

When we talk about the future population of Asia, the outlook today is very different from the one that demographers had some decades ago. At that time rapid population growth in Asia was the overriding concern. Today the population is still growing rapidly in many parts of Asia, but growth has significantly slowed in other parts, and the possibility that population growth in Asia may come to an end over the course of this century is in sight.

This paper presents the to-date unpublished results of recent probabilistic world population projections for five Asian regions. The methodology has been discussed elsewhere (Lutz . 2001) and therefore will only be summarized here.

Asia is currently in the midst of a fertility transition from high to low levels with different parts of Asia being at different stages of this transition. Although this demographic transition is assumed to be a universal phenomenon, both the speed of decline and the ultimate fertility levels are uncertain. The level of the total fertility rate (TFR) in Southeast Asia in 2030 or in China in 2050 is not yet known. But fertility is not the only uncertainty in population projections. The future trends in life expectancy and migration are equally uncertain. While it used to be widely assumed that life expectancy would increase in all countries to maximum levels of 80-85 years and then stay constant, recent studies show tremendous scientific uncertainty on this issue. Some people think that humankind is already close to the limit of the human life span, while others stress that if there is a limit, it is beyond 120 years and that already today in low mortality countries half of the girl babies born can expect to live beyond age 100. The volume of international migration is even less predictable because it is also heavily influenced by unforeseeable political developments in different parts of the world.

How should population forecasters deal with these major uncertainties? One possibility is to simply refuse to make forecasts beyond two or three decades. The problem with this attitude is that there is a demand for longer-range forecasts, especially in the context of assessing the impacts of other long-term changes such as global climate change. Complete probability-free if-then scenarios also do not fully satisfy this demand. Demographers have a lot of knowledge based on which future trends are more likely than others. The challenge is to produce forecasts that explicitly address and even quantify this uncertainty.

The currently most popular way to deal with such uncertainty - which is practiced by the UN Population Division as well as many national statistical offices - is to produce a high and low variant in addition to the medium variant which represents the future path considered most likely. The high-low range is said to cover a 'plausible range' of possible future paths. Unfortunately there are three serious problems with this 
'variants approach.' First, the variants only show the impacts of alternative future fertility paths typically assuming identical mortality and migration paths. Given the high uncertainty in these two other factors, this approach is clearly deficient. Second, it is not clear what 'plausible range' exactly means. For the user it makes a big difference whether the given range covers 100 percent or only 60 percent of all paths considered possible. Third, when national level high and low variants are aggregated to regional or global level variants, this approach becomes probabilistically inconsistent (National Research Council 2000) because it is far from certain that all countries simultaneously follow the high or low paths. In reality, trends will deviate from the expectation in different ways in different countries. Only fully probabilistic projections can deal with these problems in a satisfactory way.

\section{Different Approaches to Probabilistic Population Projections}

Since the cohort component method of projection is taken as a standard, the differences between alternative approaches discussed here refer only to the modeling of future fertility, mortality and migration rates. Here one can distinguish between (a) the specific process chosen for representing the time series of rates, and (b) the basis for the specific assumptions made about the future range of uncertainty.

In the literature there are essentially two ways of specifying the series of vital rates: (1) processes with annual fluctuations (Lee 1999; Lee and Tuljapurkar 1994; Lee and Carter 1992; Alho 1990) and (2) piece-wise linear scenarios (Lutz 1997; Lutz

1996; Lutz and Scherbov 1998). While (2) has the advantage of conforming to the current practice of scenario definition in statistical offices around the world (including the UN (1999) and the World Bank (2000)), (1) can produce realistic annual fluctuations given that the possible levels are bounded. The following moving average model with annual fluctuations has been chosen, in order to avoid the argument that the model underestimates variance (Lee 1999).

Let be a vital rate to be forecasted for periods through and the forecasted value at time . $\quad-\quad$, where the mean of , - and its standard deviation at time ,

, are determined according to the assumptions in the text. Let be the values of independent draws from a standard normal distribution and be the number of periods in the moving average. Then

The literature suggests three approaches to derive assumptions about the future range of uncertainty of the components: (1) to compute a measure of the future error from the ex post analysis of past projections (Alho 1997; Keilman 1999; Stoto 1983); (2) to apply time series models (Lee 1999; Tuljapurkar 2000; Lee and Tuljapurkar 1994); and (3) to have well informed experts make assumptions based on explicitly stated substantive arguments (Lutz 1999). These three approaches are not mutually exclusive and (1) and (2) also include expert judgment.

In this set of probabilistic projections, a step toward a synthesis of the three approaches is taken. The process specification uses a time series model. Existing national level parameter estimates (Lee and Tuljapurkar 1994; Lee and Carter 1992) have been explicitly considered, although at the level of world regions, empirical 
estimation is impossible due to lack of data. The ex post analysis of past errors enters this study in two ways: The substantive assumptions made on fertility and mortality changes are informed by the analysis of past errors in those components (National Research Council 2000; Keilman 1999) and the results at the regional level have been compared to the results of an ex post error analysis of global UN projections documented in the National Research Council (2000) report. Since for the specific purpose of this paper it was preferred to err on the side of higher variance (i.e., lower probability of population growth ending this century) the general rule was followed, to produce intervals that were at least as large as those in the National Research Council (2000) report at the level of major world regions. Combining this with argument-based expert judgment (Lutz 1996), substantive reasons were found for assuming a larger uncertainty in many regions due to new factors such as HIV/AIDS, the new situation in the former USSR and the indeterminancy of long-range, post-transitional fertility levels affecting an increasing number of countries.

\section{Assumptions}

The key determinant of the timing of the peak in population size is the assumed speed of fertility decline in the parts of Asia that still have high fertility. On this issue there is a broad consensus that fertility transitions are likely to be completed in the next few decades (National Research Council 2000). For the eventual size of the population and the question of whether or not world population will begin a decline by the end of this century the key variable is the assumed level of post-transitional fertility. The thorough review of the literature on that subject by the National Research Council states that "fertility in countries that have not completed transition should eventually reach levels similar to those now observed in low fertility countries" (National Research Council 2000:106). The fertility assumptions given here are consistent with this view.

The trends in the means of the regional fertility levels have been defined for the periods 2025-29 and 2080-84 with interpolations in between. The total fertility rates assumed for 2025-29 are similar to those chosen by the UN (1999), but for 2080-84 they are assumed to range between 1.5 and 2.0, with lower levels for regions with higher population density in 2030 . The variances in the total fertility rates are assumed to depend on the level of fertility. If the TFR is above 3.0 there is an 80 percent chance that fertility would be within one child of the mean. When it is below 2.0, the same probability is attached to a range within one half a child of the mean. Between the two TFR levels, the variance is interpolated.

Life expectancy at birth was assumed to rise in all five Asian regions studied here. Generally, it is assumed that life expectancy increases by two years per decade with an 80 percent probability that the increase is between zero and four years, with a number of exceptions to this rule based on specific regional conditions. These assumptions reflect the very large uncertainty that exists regarding future mortality conditions. On the one hand, significant bio-medical breakthroughs are likely to be made; on the other hand, AIDS could still become a major issue outside Africa, and new and unexpected threats to human life can emerge.

Migration is treated as a random vector based on recent interregional migration patterns. The autocorrelation chosen for all components is based on a 31-year moving average process which was the most plausible after experimenting with 21,31 and 41 
years, and is close to existing national level figures (Lee 1999). An interregional correlation of 0.7 for fertility and 0.9 for mortality deviations was assumed, with no correlation between fertility and mortality deviations from the assumed trend, and perfect correlation between male and female life expectancy. The main rationale behind this choice is that under post-transition conditions, correlations between deviations from assumed fertility and mortality trends are unlikely to be large, while globalization of communication is likely to bring correlated fluctuations of rates among world regions. Mortality correlations will be higher than fertility correlations due to the faster communication of medical technology and the faster spread of new health hazards.

\section{Results}

Based on these assumptions 1,000 independent cohort component simulations were carried out for each region by randomly drawing from the uncertainty distributions for fertility, mortality and migration using the specified correlations. The resulting distributions for the five Asian regions (see Appendix Map) and for all five regions together are presented in terms of the fractiles of the distributions in the following graphs. The quantitative data for all five regions and different demographic indicators are given in the Appendix Tables 1-5.

Figure 1 gives the cumulative probabilities that the population size of the specified region will reach a peak at or before the stated point in time. For the global level Lutz . (2001) estimated a probability of roughly 85 percent that the world population will reach a peak before the end of the century. For all five Asian regions together the pattern is rather similar to the global one. Mostly because of momentum, the probability that the total Asian population will reach a peak (followed by a decline) is close to zero until around 2020. Then it slowly starts to increase. By 2060 there is about a 50 percent chance that the Asian population will have peaked. By the end of the century the chance is about 90 percent.

The patterns in Figure 1 are quite diverse for the different parts of Asia. The highest probability of peaking is in the Pacific OECD region, which is clearly dominated by the trends in Japan. There, the probability of a peak increases rapidly over time with a 50 percent chance reached around 2025. By 2050 the chance of peaking increases to around 70 percent. Interestingly, the China region reaches the same level by the same time, but shows a very different path during the first half of the century. Due to the great age structural momentum in China - the steep fertility decline was more recent here than in Japan - the probability of peaking is close to zero over the next 15 years. During the 2020s and 2030s it is expected to increase precipitously and catch up with the Asian OECD countries by the middle of the century. South Asia clearly shows the lowest probabilities of reaching a peak because of its still rather high fertility. By the middle of the century the chance that South Asia will have reached a peak is below 10 percent. During the second half of the century, the chance is expected to increase based on the assumption of long-term, below-replacement fertility, even on the Indian subcontinent.

Figures 2 and 3 contrast the uncertainty distributions for future population size in China and South Asia. The shading in the graphs refers to the fractiles stated at the right margin. The lightest shading gives the 95 percent interval; the medium shading shows the inner 60 percent; and the darkest shows the inner 20 percent of output 
distributions generated by the set of simulations. The white line gives the median of the distribution. As can be expected, in all cases the uncertainty increases with time. For the China region, the median of the distributions shows an increase until a peak around 2030-35, followed by a decline. The distribution also shows that there is at least a 20 percent chance that the population of China will continue to grow into the second half of this century. But there is a chance of more than 60 percent that the population of China in 2100 might be lower than it is today. In contrast, the projections for South Asia show a very likely increase well into the second half of the century. For South Asia, the chance that the population size in 2100 will be lower than it is today is only less than 20 percent.

Using the example of age distribution in China, Figure 4 shows that the likely end of population growth comes with a very significant reduction in the proportion of children and youth below age 20 . The decline is clearly pre-programmed in the age structure for the coming three to four decades. Thereafter, the proportion of children will greatly depend on the future level of fertility, in addition to the uncertain number of future mothers.

Figure 5 shows the uncertainty distribution for the proportion above age 60 in the example of Pacific Asia (which essentially includes the countries of Southeast Asia). Here the trend over the coming three to four decades shows even less uncertainty than for the proportion of children because most of the people concerned have already been born und the remaining uncertainty refers mostly to mortality and migration uncertainty. A doubling of the proportion above age 60 over the next 40 years is almost a certainty. Further significant increases during the rest of the century are also very likely, although the uncertainty range significantly increases with time. Over the course of the century the proportion of elderly in this region of Asia will likely quadruple, certainly more than double, and possibly even increase by a factor of eight.

Figure 6 gives an even more astonishing feature of population aging. It shows the expected increases in the proportion above age 80 for the Pacific OECD region. At present, 3.5 percent of the population is above that age. This proportion is expected to increase quickly over the coming decades. Due to the great uncertainty about future gains in life expectancy, by the end of the century, the 95 percent range goes from around 5 percent - which is not much higher than the current level - to an incredible 46 percent of the population above age 80 . Even the median shows a very high 25 percent of the population above age 80 in 2100 . This extremely broad range is clearly a function of the broad uncertainty distribution assumed for future gains in life expectancy. Without having the space to discuss the specific assumptions here, this pattern clearly illustrates that alternative mortality assumptions do make a major difference and that population projections that disregard mortality uncertainty in the definition of their variants (such as the UN projections and those of many national statistical offices) clearly fail to capture an important source of uncertainty of future population changes.

Figure 7 gives the old age dependency ratio defined here as the population above age 60 divided by the population aged 20 to 60, for the example of Central Asia. It is amazing to see that over the coming 25 years there is practically no uncertainty. The ratio will slightly decrease, then increase again. Since the sizes of the cohorts are already known, the only minor uncertainties here relate to near-term mortality and migration trends. For the second half of the century, however, uncertainty greatly 
increases and by 2100 , distribution shows that with a 95 percent chance, the dependency ratio will lie between 0.4 and 1.5. This significant uncertainty is a consequence of cumulating mortality and fertility uncertainties, both of which crucially affect the old age dependency ratio in the long run.

Figure 8 shows the complete probabilistic age pyramid for the example of Pacific Asia in 2050. It nicely illustrates how significantly the uncertainty ranges differ among age groups. Because the birth year of the cohort is a key dimension for understanding the pattern, it is listed on the right vertical axis. It is evident that the base year of the projections, the year 2000, represents a watershed in the degree of uncertainty. The initial size of the cohorts born before 2000 is already known. Since mortality rates are rather low for young adults, the uncertainty range is lowest for those cohorts born between 1990 and 2000. The older the cohorts get, the bigger the uncertainty range due to the uncertainty in future old age mortality trends. These uncertainties are small, however, as compared to the distributions for cohorts born after 2000 , since for those, one does not know the initial cohort size. For cohorts to be born around 2025-30, a further broadening of the distribution is visible because the uncertainty of future fertility rates begins to become superimposed on the uncertainty of the cohort size of potential mothers.

\section{Conclusions}

This paper has applied, for the first time, a probabilistic population projection framework to all of Asia and its sub-regions. Such a framework can help to illustrate the uncertainties associated with future demographic trends and, in particular, show how these uncertainties differ by age, by the demographic indicator chosen, and by regions. In addition, it has been illustrated how the assumed uncertainty about future gains in life expectancy results in very significant uncertainties about the future size of the oldest age groups, implying that conventional projection variants that are only based on alternative fertility assumptions may be grossly misleading with respect to the resulting uncertainty ranges.

Substantively, this set of simulations has shown that even in the unlikely case of very rapid fertility declines and very low future fertility levels, combined with no gains in life expectancy, the population growth in Asia will certainly not come to an end in the near future. Only in the Pacific OECD region could such extreme trends result in a near term population decline. In all other regions the young age structure of the population and the resulting momentum will result in continued growth in the near term future. Beyond the next three to four decades, however, a key determinant will be the long-term fertility level. Sub-replacement fertility is a definitive longer-term possibility for most parts of Asia. Eventually, this will result in a leveling off of population growth and is likely to be followed by a population decline. This study has illustrated that there is indeed a high probability that during the second half of this century Asia will experience the end of population growth. 


\section{References}

Alho, J.M. 1997. Scenarios, uncertainty and conditional forecasts of the world population. 160:71-85.

Alho, J.M. 1990. Stochastic methods in population forecasting. 6:521-530.

Keilman, N. 1999. How accurate are the United Nations world population projections? Pages 15-41 in W. Lutz, J.W. Vaupel, and D.A. Ahlburg (eds), Supplement to (1998).

Lee, R.D. 1999. Probabilistic approaches to population forecasting. Pages 156-190 in W. Lutz, J.W. Vaupel, and D.A. Ahlburg (eds), . Supplement to 24 (1998).

Lee, R.D. and L. Carter. 1992. Modeling and forecasting the time series of U.S. mortality. 87:659-671.

Lee, R. and S. Tuljapurkar. 1994. Stochastic population projections for the United States: beyond high, medium and low.

89:1175-1189.

Lutz, W. (ed). 1996.

Revised Edition. London: Earthscan.

Lutz, W. and S. Scherbov. 1998. An expert-based framework for probabilistic national population projections: the example of Austria.

14:1-17.

Lutz, W., W. Sanderson and S. Scherbov. 2001. The end of world population growth. 412:543-545.

Lutz, W., W. Sanderson and S. Scherbov. 1999. Expert-based probabilistic population projections. Pages 139-155 in W. Lutz, J.W. Vaupel, and D.A. Ahlburg (eds), 24 (1998).

- Supplement to

$$
24(1998) \text {. }
$$

Lutz, W., W. Sanderson and S. Scherbov. 1997. Doubling of world population unlikely. 387:803-805.

Lutz, W., W. Sanderson and S. Scherbov. 1996. Probabilistic population projections based on expert opinion. Pages 397-385 in W. Lutz (ed.),

Earthscan.

Revised Edition. London:

National Research Council. 2000.

. Panel on Population Projections. John Bongaarts and Rodolfo A. Bulatao (eds). Committee on Population, Commission on Behavioral and Social Sciences and Education. Washington, D.C.: National Academy Press.

Stoto, M. 1983. The accuracy of population projections. 78:13-20. 
Tuljapurkar, S., N. Li and C. Boe. 2000. A universal pattern of mortality decline in the G7 countries. 405:789-792.

UN. 1999.

New York: United Nations, ESA/P/WP.153.

World Bank. 2000.

(CD-ROM). Washington, D.C.:

World Bank. 
Figure 1. Cumulative probability of peaking.

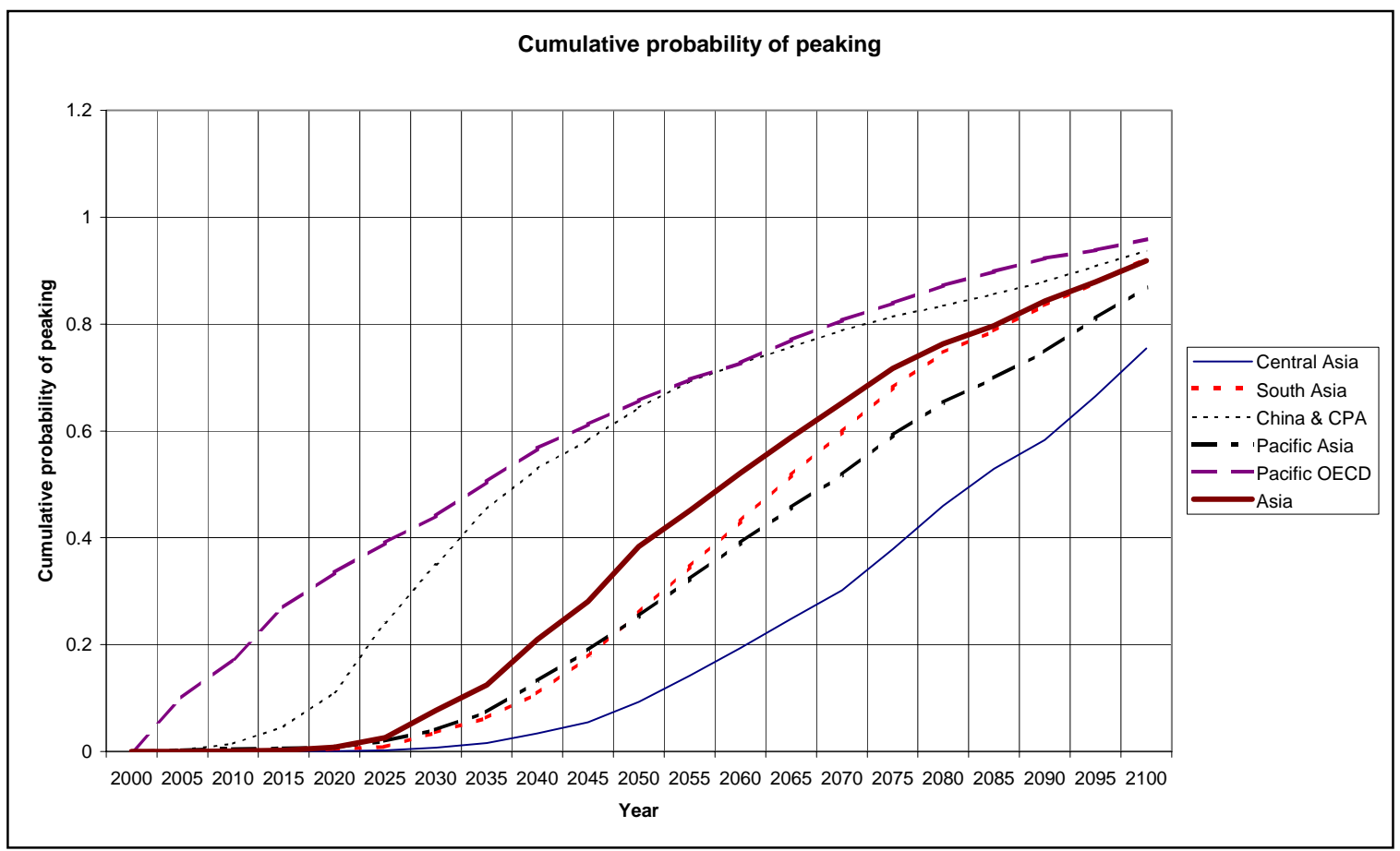

Figure 2. Total population of China and CPA (in billions).

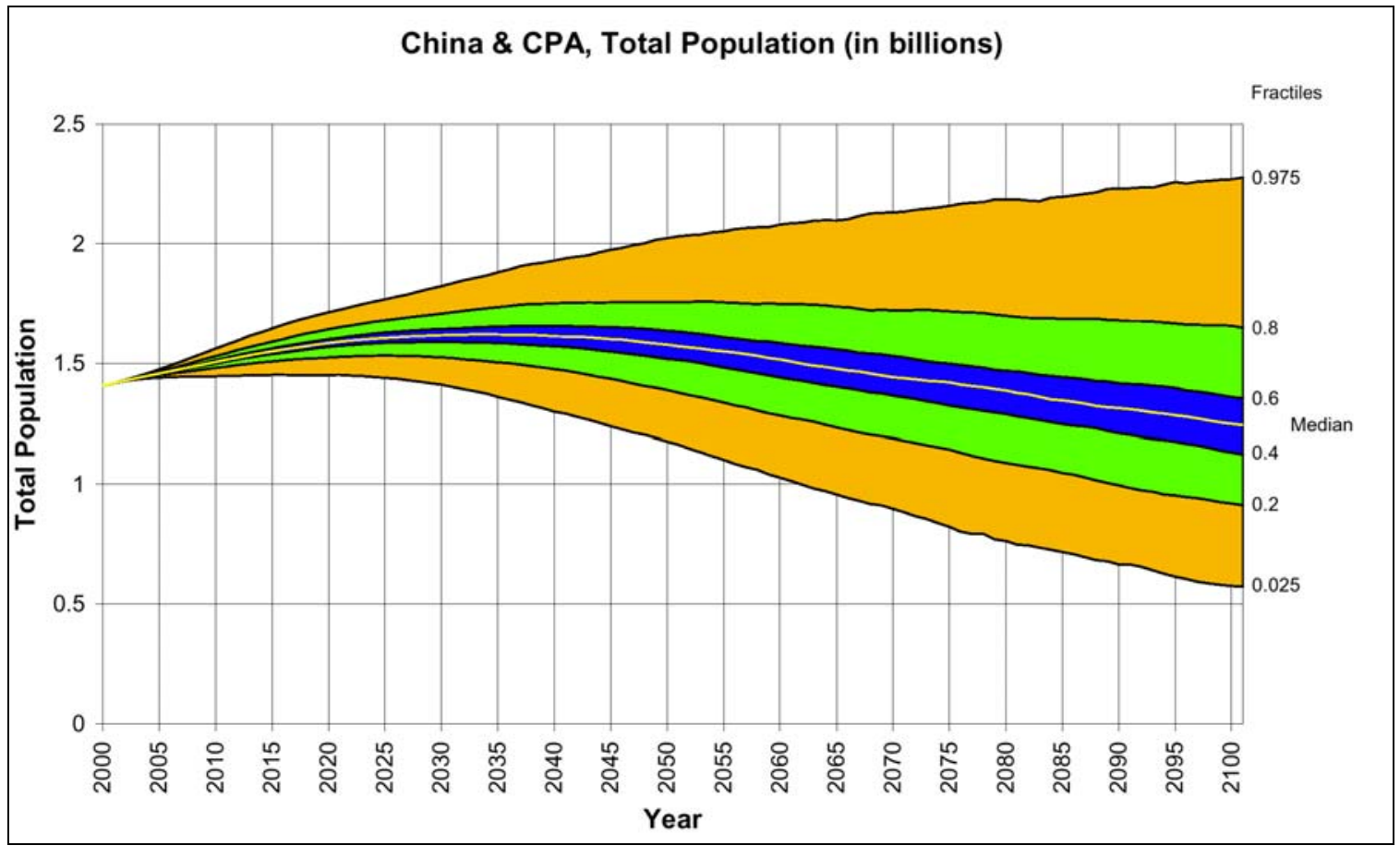


Figure 3. Total population of South Asia (in billions).

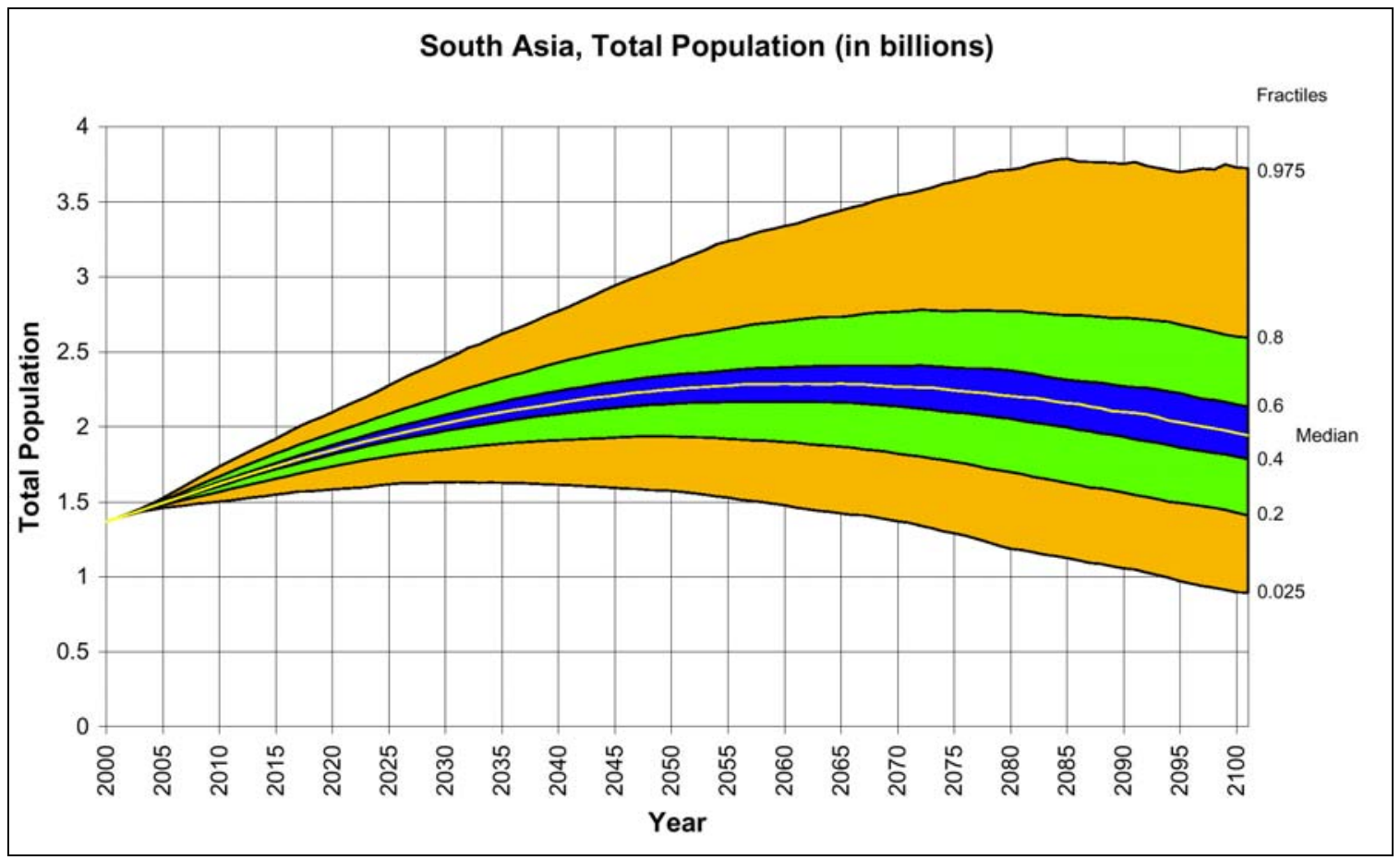

Figure 4. Proportion below age 20 in China and CPA.

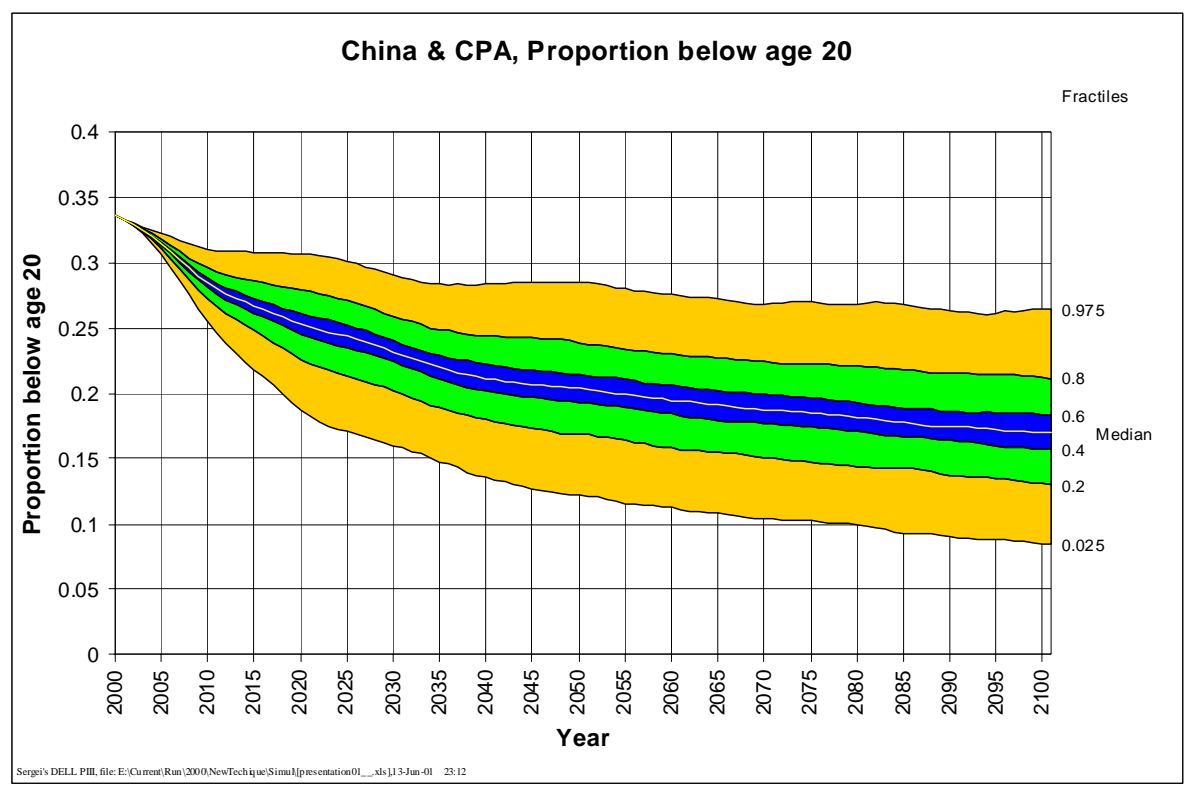


Figure 5. Proportion above age 60 for Pacific Asia.

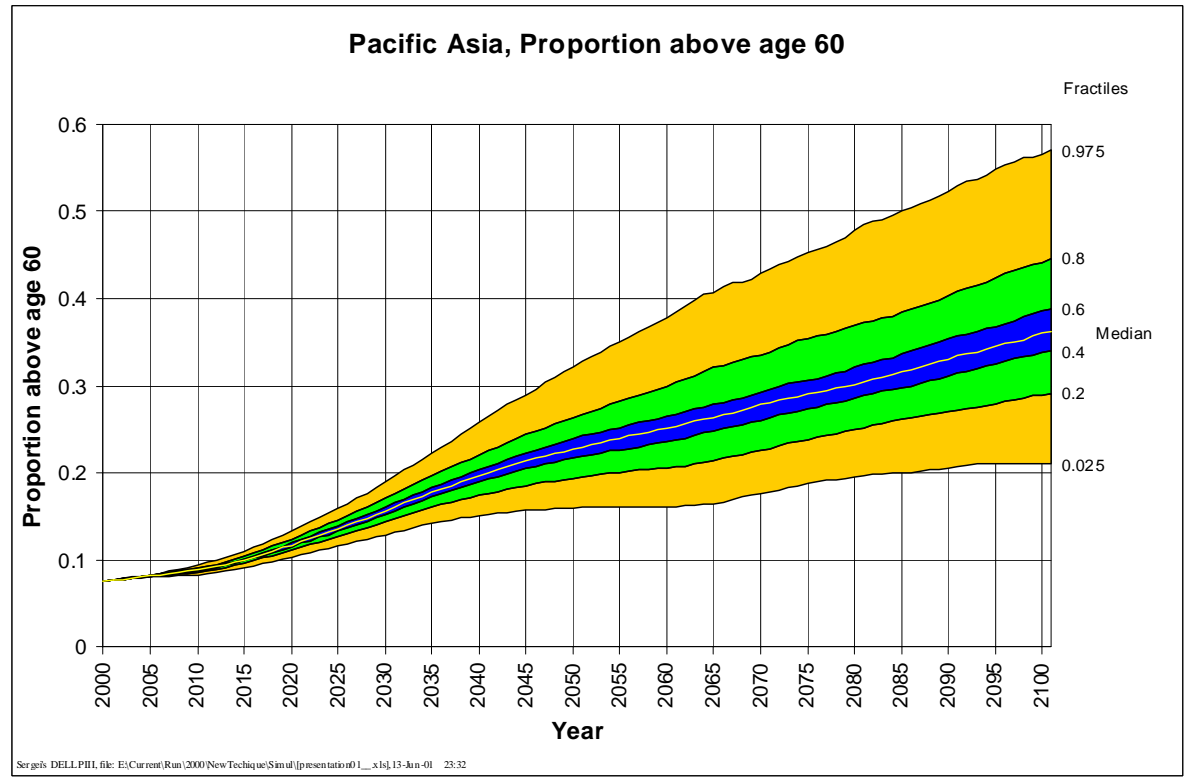

Figure 6. Proportion above age 80 for Pacific OECD.

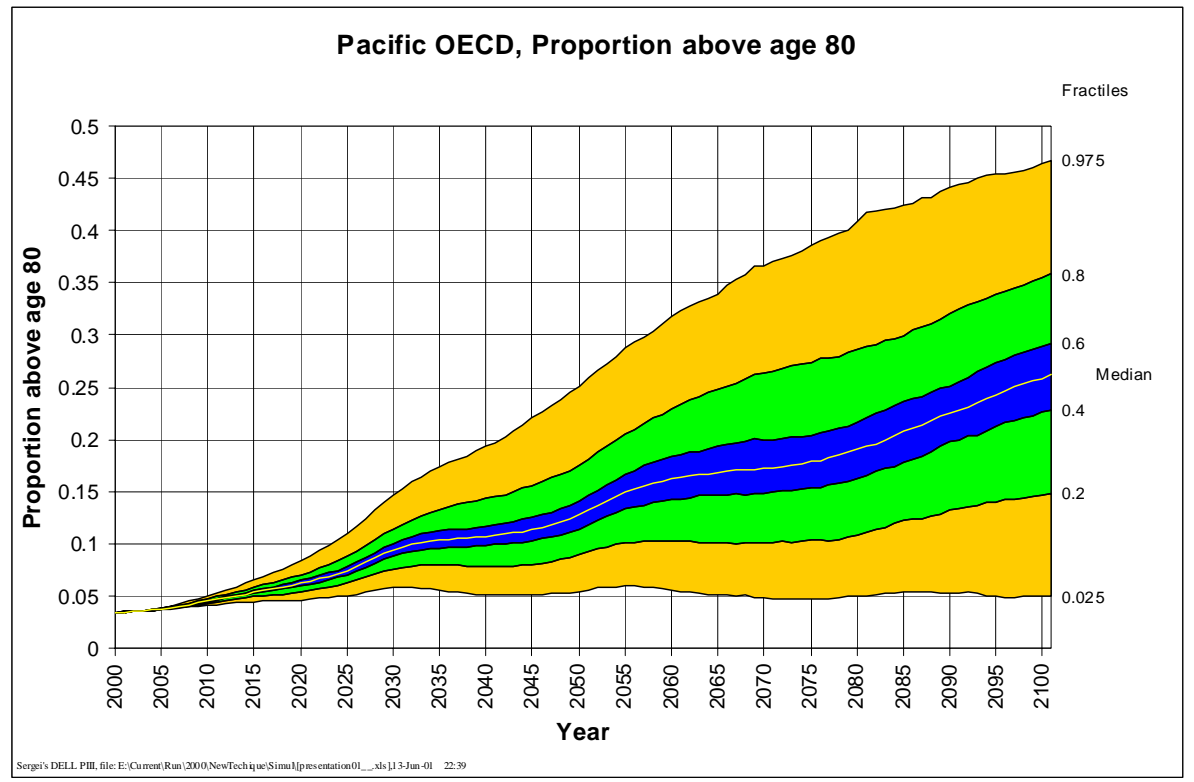


Figure 7. Old age dependency ratio (60+ / 20-60) for Central Asia.

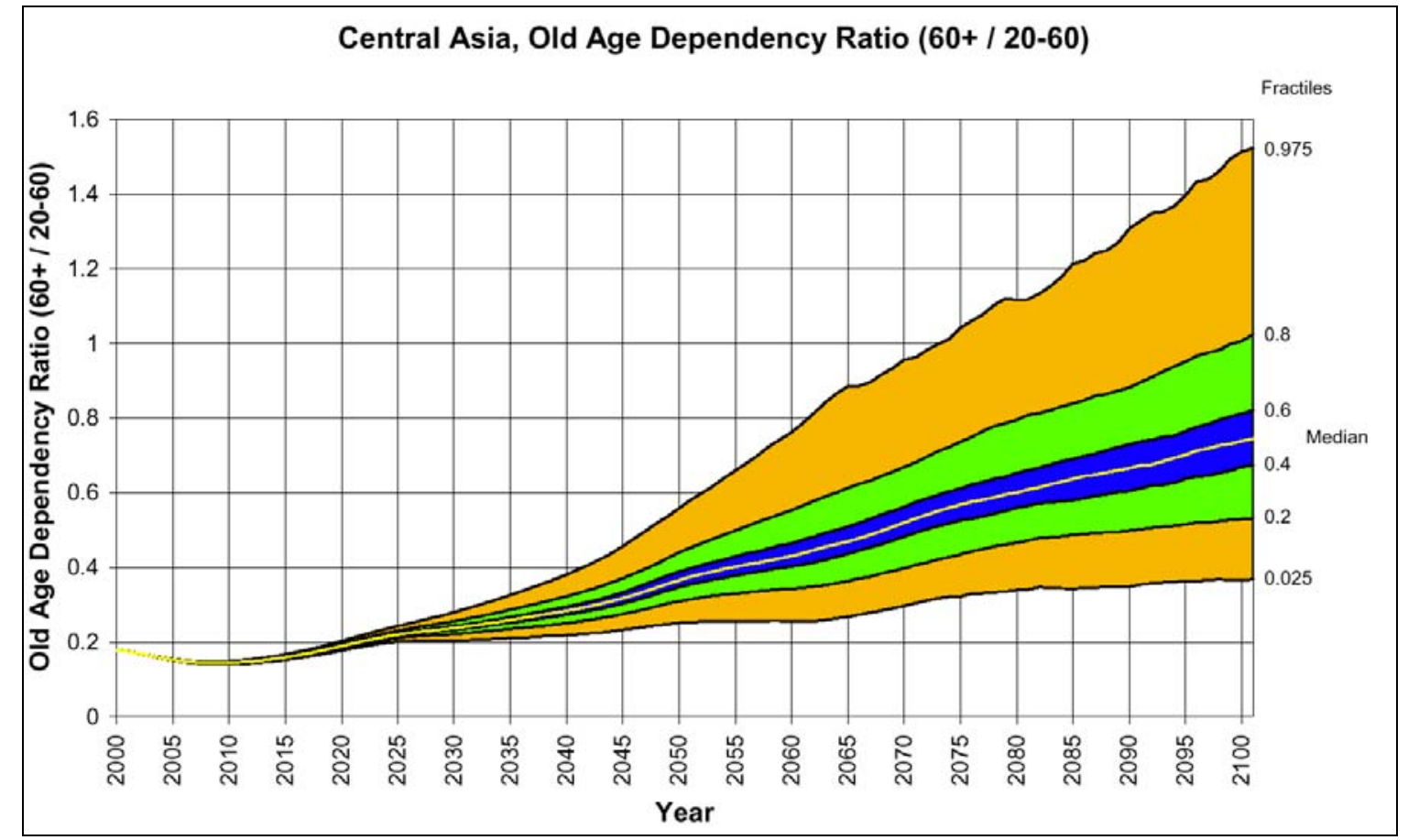

Figure 8. Pacific Asia, 2050 (in millions).

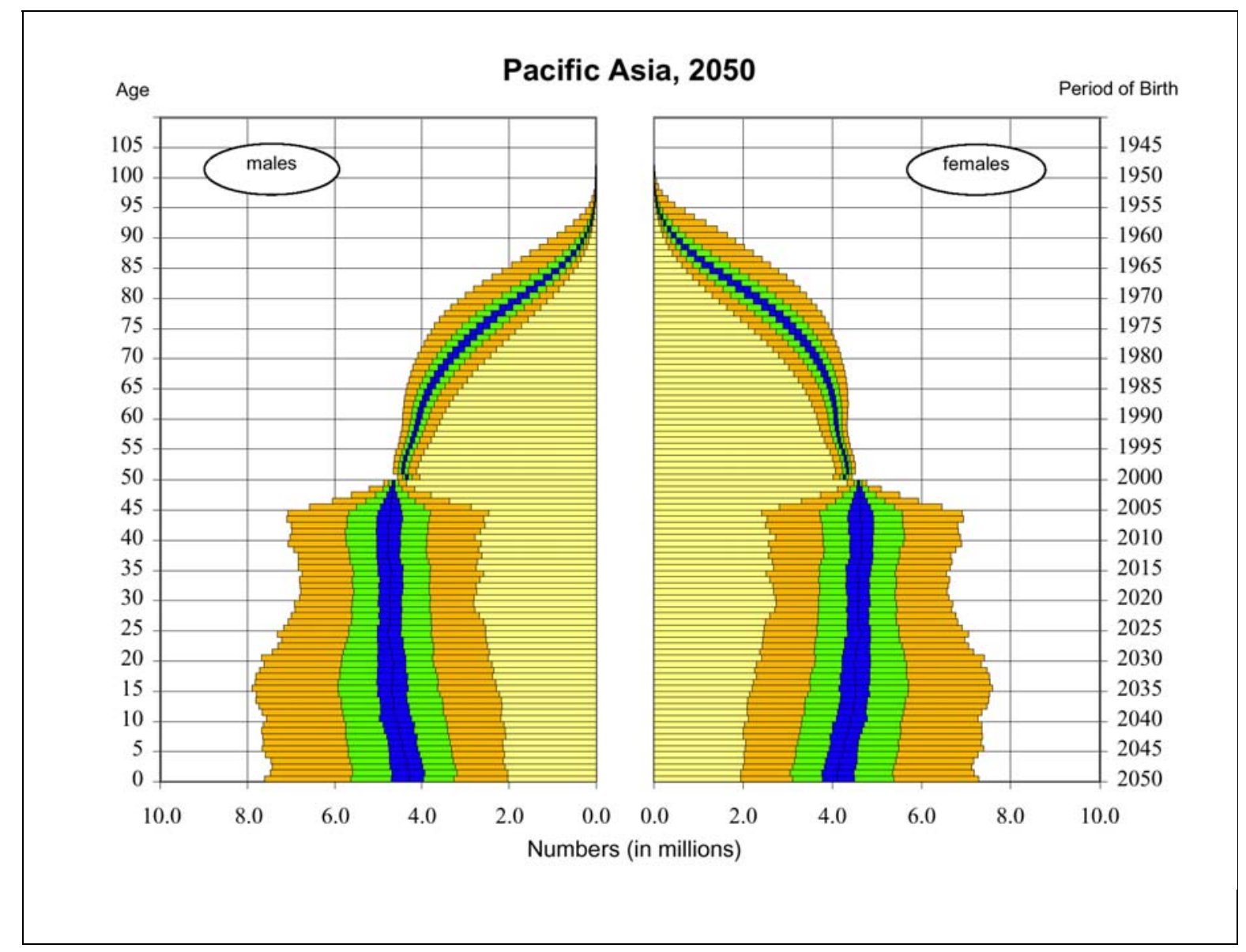


Appendix Table 1. Total population. Median and 80 percent intervals.

\begin{tabular}{|c|c|c|c|c|c|}
\hline & 2000 & 2025 & 2050 & 2075 & 2100 \\
\hline Central Asia & & 81.373 & 99.811 & 107.061 & 105.811 \\
\hline (in millions) & 55.877 & $(72.796-89.910)$ & (79.558-120.973) & (75.511-145.089) & $(66.065-159.488)$ \\
\hline South Asia & & 1.940 & 2.249 & 2.242 & 1.958 \\
\hline (in billions) & 1.367 & $(1.735-2.154)$ & $(1.795-2.776)$ & $(1.528-3.085)$ & (1.186-3.035) \\
\hline China \& CPA & & 1.608 & 1.580 & 1.422 & 1.250 \\
\hline (in billions) & 1.408 & (1.494-1.714) & $(1.305-1.849)$ & $(1.003-1.884)$ & $(.765-1.870)$ \\
\hline Pacific Asia & & 625.135 & 701.586 & 702.403 & 653.580 \\
\hline (in millions) & 476.426 & $(568.846-682.233)$ & (575.128-842.238) & $(508.969-936.758)$ & $(410.029-948.948)$ \\
\hline Pacific OECD & & 154.557 & 148.347 & 135.024 & 122.701 \\
\hline (in millions) & 149.935 & (143.762-165.010) & (124.643-173.823) & $(99.549-174.745)$ & (79.354-172.714) \\
\hline $\begin{array}{l}\text { Asia } \\
\text { ( } 5 \text { regions) } \\
\text { (in billions) }\end{array}$ & 3.457 & $\begin{array}{c}4.415 \\
(4.058-4.782)\end{array}$ & $\begin{array}{c}4.781 \\
(3.971-5.703)\end{array}$ & $\begin{array}{c}4.630 \\
(3.394-6.101)\end{array}$ & $\begin{array}{c}4.114 \\
(2.684-6.085)\end{array}$ \\
\hline
\end{tabular}

Appendix Table 2. Proportion below age 20. Median and 80 percent intervals.

\begin{tabular}{lccccc}
\hline & 2000 & 2025 & 2050 & 2075 & 2100 \\
\hline Central Asia & & .355 & .273 & .227 & .196 \\
& 0.45 & $(.291-.408)$ & $(.215-.327)$ & $(.172-.278)$ & $(.142-.254)$ \\
South Asia & & .357 & .265 & .205 & .163 \\
& 0.45 & $(.289-.410)$ & $(.206-.317)$ & $(.152-.260)$ & $(.109-.218)$ \\
China \& CPA & & .243 & .204 & .185 & .170 \\
& 0.336 & $(.196-.284)$ & $(.148-.257)$ & $(.129-.244)$ & $(.112-.234)$ \\
Pacific Asia & & .310 & .254 & .210 & .173 \\
& 0.398 & $(.255-.359)$ & $(.199-.303)$ & $(.154-.260)$ & $(.115-.232)$ \\
Pacific OECD & & .188 & .179 & .162 & .140 \\
& 0.218 & $(.149-.227)$ & $(.127-.225)$ & $(.108-.214)$ & $(.088-.198)$ \\
Asia & & & & & \\
$(5$ regions) & .387 & $(.252-.349)$ & $(.193-.287)$ & $(.151-.248)$ & $(.118-.222)$ \\
\hline
\end{tabular}

Appendix Table 3. Proportion above age 60. Median and 80 percent intervals.

\begin{tabular}{lccccc}
\hline & 2000 & 2025 & 2050 & 2075 & 2100 \\
\hline Central Asia & & .117 & .194 & .279 & .340 \\
& 0.083 & $(.104-.131)$ & $(.153-.250)$ & $(.206-.373)$ & $(.238-.459)$ \\
South Asia & & .104 & .177 & .271 & .351 \\
& 0.07 & $(.093-.117)$ & $(.141-.229)$ & $(.204-.361)$ & $(.253-.475)$ \\
China \& CPA & & .188 & .303 & .350 & .393 \\
& 0.099 & $(.172-.205)$ & $(.243-.371)$ & $(.257-.470)$ & $(.267-.531)$ \\
Pacific Asia & & .136 & .227 & .290 & .360 \\
& 0.076 & $(.123-.151)$ & $(.180-.285)$ & $(.215-.389)$ & $(.257-.489)$ \\
Pacific OECD & & .319 & .390 & .427 & .491 \\
& 0.22 & $(.290-.350)$ & $(.312-.469)$ & $(.312-.549)$ & $(.349-.618)$ \\
Asia & & & & & \\
$(5$ regions $)$ & .089 & $(.133-.161)$ & $(.187-.286)$ & $(.230-.395)$ & $(.265-.489)$ \\
\hline
\end{tabular}


Appendix Table 4. Proportion above age 80 . Median and 80 percent intervals.

\begin{tabular}{lccccc}
\hline & 2000 & 2025 & 2050 & 2075 & 2100 \\
\hline Central Asia & & .009 & .028 & .064 & .110 \\
& 0.008 & $(.008-.012)$ & $(.018-.048)$ & $(.031-.130)$ & $(.043-.225)$ \\
South Asia & & .009 & .020 & .046 & .088 \\
& 0.006 & $(.008-.010)$ & $(.014-.032)$ & $(.025-.098)$ & $(.039-.201)$ \\
China \& CPA & & .018 & .062 & .100 & .143 \\
& 0.009 & $(.015-.022)$ & $(.041-.100)$ & $(.049-.200)$ & $(.052-.292)$ \\
Pacific Asia & & .012 & .035 & .066 & .111 \\
& 0.006 & $(.011-.015)$ & $(.023-.059)$ & $(.032-.140)$ & $(.045-.234)$ \\
Pacific OECD & & .075 & .129 & .179 & .258 \\
& 0.035 & $(.058-.096)$ & $(.073-.207)$ & $(.075-.322)$ & $(.097-.402)$ \\
Asia & & & & & \\
(5 regions) & .008 & $(.013-.018)$ & $(.026-.064)$ & $(.037-.139)$ & $(.049-.235)$ \\
\hline
\end{tabular}

Appendix Table 5. Old age dependency ratio (60+ / 20-60). Median and 80 percent intervals.

\begin{tabular}{lccccc}
\hline & 2000 & 2025 & 2050 & 2075 & 2100 \\
\hline Central Asia & & .220 & .366 & .568 & .738 \\
& 0.178 & $(.206-.236)$ & $(.285-.485)$ & $(.385-.851)$ & $(.458-1.177)$ \\
South Asia & & .193 & .318 & .524 & .724 \\
& 0.146 & $(.183-.206)$ & $(.253-.417)$ & $(.366-.774)$ & $(.461-1.189)$ \\
China \& CPA & & .329 & .614 & .757 & .905 \\
& 0.175 & $(.307-.355)$ & $(.475-.804)$ & $(.499-1.214)$ & $(.512-1.542)$ \\
Pacific Asia & & .246 & .438 & .581 & .783 \\
& 0.144 & $(.230-.264)$ & $(.340-.573)$ & $(.398-.894)$ & $(.484-1.285)$ \\
Pacific OECD & & .649 & .908 & 1.037 & 1.340 \\
& 0.392 & $(.578-.725)$ & $(.667-1.218)$ & $(.643-1.664)$ & $(.755-2.184)$ \\
\hline
\end{tabular}


Appendix Map. Definition of the five regions. 